\title{
Guest editorial: Molybdenum alloying: more than hardenability
}

\author{
Hardy Mohrbacher ${ }^{1,2}$ (1)
}

Received: 28 May 2019/Revised: 30 May 2019/Accepted: 31 May 2019/Published online: 14 June 2019

(C) The Author(s) 2019

Molybdenum is a transitional metal in the periodic table of elements where it ranks in position 42 in the 5 th period and group V1 B. Having a high melting point of $2623{ }^{\circ} \mathrm{C}$, molybdenum belongs to the so-called refractory metals. Accordingly, as pure metal it finds many applications where high temperatures are encountered during operation, for example in furnaces. However, nearly $80 \%$ of all molybdenum produced every year by the world's mining industry is used as addition to iron and steel alloys. Carbon and alloy steels account for $40 \%$ of molybdenum use, followed by stainless steels (23\%), tool steels and castings (both around 8\%).

The widespread use of molybdenum as alloying element is due to its unique metallurgical effects. Molybdenum is commonly known for enhancing hardenability of iron and steel alloys. Furthermore, it forms carbides when a sufficient amount of carbon is present in the alloy. Both effects enable the production of strong and wear resistant alloys. It therefore, traditionally, is a constituent of many heat treatable steels and tool steels. Respective research efforts have been reported as early as the 1930s. More widespread use of molybdenum in the steel industry appeared in the 1960s when Climax Molybdenum Company initiated a substantial and remarkable market development program exploring new potential applications. These applications typically demanded higher strength of the final product yet also sufficient toughness, resistance against softening at elevated temperatures of operation or corrosion resistance. Increasingly, manufacturing and fabricating of parts,

Hardy Mohrbacher

hm@niobelcon.net

NiobelCon bvba, Schilde, Belgium

2 Department of MTM, KU Leuven, Leuven, Belgium components, installations and equipment came into focus requiring particular attention to forming and welding behavior of steel products. This led to the evolution of high strength low alloy (HSLA) steels, which became a workhorse material for the oil \& gas industry in the early 1970s and had pertained ever since at further increasing strength levels. Similar types of HSLA steels soon conquered the constructional arena and somewhat later the automotive industry. The motivation for the use of these steels has always been similar: to enhance efficiency, improve performance in operation and facilitate manufacturing. Molybdenum is a key alloying element in bridging these often mutually contradictory requirements.

With the upgrading of steelmaking facilities in the industrialized countries starting in the later 1970s, the use of molybdenum in some of the mainstream alloys became obsolete. The advent of thermo-mechanical rolling and accelerated cooling could provide sufficient hardenability to achieve medium strength levels using rather lean-alloyed steel. Today, as a general rule, it can be stated that molybdenum becomes relevant in steels with a yield strength of $500 \mathrm{MPa}$ or more. Exceptions in lower strength levels may apply when particularly heavy gages need to be produced. On the other hand, thin gages would require molybdenum alloying only at an even higher strength level. Fortunately, the trend in steel development is proceeding towards much higher strength grades. Many applications in mechanical engineering nowadays, demand material having a yield strength of at least $700 \mathrm{MPa}$ and carmakers routinely use steel grades of over $1000 \mathrm{MPa}$ strength for a large share of the vehicle structure. Accordingly, the challenges with regard to manufacturing and fabrication are increasing further.

Molybdenum alloying has clearly regained its relevance in this modern steel age. It is not being displaced anymore 
from alloys by more capable metallurgical processes. On the contrary, often molybdenum alloying actually enables using the full potential of most modern steelmaking equipment. It also enhances efficiency of secondary treatments, thus contributing to sustainability and cost reduction. Furthermore, molybdenum alloying facilitates the use of established manufacturing processes when producing components from such advanced steel grades. Last but not least, the performance of ultra-high strength steels under operational conditions requires increased attention. The demand for sufficient toughness at high strength level has been around for decades and continues to be of high importance. A new challenge, at ultra-high strength level, is the resistance of steel to hydrogen embrittlement. Hydrogen can accumulate in steel during steel processing, fabrication processes such as welding or surface treatments or during operation by corrosion phenomena and can cause the steel to crack. Another challenge is to retain the very high strength of steel at high temperatures, be it during operation or during intermediate processing such as heat treatment or welding. In all these cases molybdenum alloying offers proven, viable solutions to the challenges.

In the casting industry, a similar evolution towards higher performing materials has been developing. In contrast to the steel industry, the possibilities of upgrading material properties by thermo-mechanical processing, using lean alloy concepts, are rather limited in the foundry industry. In other words, alloying continues to play a relatively more important role in this sector. Not surprisingly molybdenum alloying is prominent in cast iron and steel products, again for promoting strength, toughness, heat resistance and wear resistance.

The Chinese metallurgical industry is by far the largest in the world for both steel production and castings. In each sector China accounts for approximately half of the annual world production. Major investments in state-of-the-art metallurgical processing equipment have been made since the beginning of the millennium. Over less than two decades, Chinese steelmakers have succeeded in developing leading edge products, and have made increasing use of the potential offered by their modern equipment. China is also one of the three major molybdenum mining hubs in the world. Considering its annual molybdenum output, the country is largely self-sufficient in molybdenum supplies to the metallurgical industry. Hence, molybdenum alloying should be a natural choice when producing high performance iron and steel alloys.

The amount of molybdenum added to an alloy spans from as little as $0.1 \%$ in HSLA steels to around $9 \%$ in tool steels. The question of how much molybdenum should be added in a specific application is usually answered by considering a balance of performance gain on the one hand and cost optimization on the other hand. Comprehensive research is needed to unravel the full benefits of molybdenum alloying for justifying the alloy cost. Ideally this argumentation includes a holistic consideration of processing, manufacturing and end use. However, a small amount of molybdenum typically goes a long way in increasing strength of steels and irons while keeping their toughness intact. Using a higher strength steel allows the engineer to reduce the gage for a given application, leading to a lighter structure, but also to significant savings in the amount of steel required. In that sense, adding as little as $0.1 \%-0.2 \%$ of molybdenum to a steel to increase its strength can save tonnes of steel, making the application more sustainable. The International Molybdenum Association (IMOA), being the voice of the global molybdenum industry, is fully dedicated to molybdenum market development amongst many other services offered to its members. IMOA has been consolidating molybdenum-related knowledge and know-how gained over the decades and is making it available to the metallurgical industry with the clear intention of finding the most sustainable solution.

In order to facilitate knowledge exchange with the Chinese metallurgical industry and to fertilize new alloy development, an International Symposium on Applications of Molybdenum in the Iron and Steel Industry was organized in Shanghai in November 2018. The event was coorganized and hosted by the Center of Advanced Solidification Technology (CAST) at Shanghai University. More than 100 Chinese and international experts participated in this symposium presenting and discussing the many beneficial facets that molybdenum alloying offers. This was the second event of its kind in China after a first symposium held in Beijing in the year 2010, that time in cooperation with the Central Iron \& Steel Research Institute (CISRI). The following four papers provide a summary of the presented and discussed information in the major application areas flat carbon steels, engineering steels and castings as well as an overview of the Chinese molybdenum industry.

Open Access This article is distributed under the terms of the Creative Commons Attribution 4.0 International License (http://crea tivecommons.org/licenses/by/4.0/), which permits unrestricted use, distribution, and reproduction in any medium, provided you give appropriate credit to the original author(s) and the source, provide a link to the Creative Commons license, and indicate if changes were made. 